\title{
Effects of Smad4 on the expression of caspase-3 and Bcl-2 in human gingival fibroblasts cultured on 3D PLGA scaffolds induced by compressive force
}

\author{
SHUANG ZHAO, LAN NAN, YAO WANG, LIYING WEI and SHUIXUE MO \\ Department of Stomatology, Guangxi Medical University, Nanning, Guangxi 530021, P.R. China
}

Received July 6, 2020; Accepted November 30, 2020

DOI: $10.3892 /$ ijmm.2021.4858

\begin{abstract}
Human gingival fibroblasts (HGFs) are the main cells that comprise gingival tissue, where they transfer mechanical signals under physiological and pathological conditions. The exact mechanism underlying gingival tissue reconstruction under compressive forces remains unclear. The present study aimed to explore the effects of Smad4, caspase-3 and Bcl-2 on the proliferation of HGFs induced by compressive force. HGFs were cultured on poly(lactide-co-glycolide) (PLGA) scaffolds under an optimal compressive force of $25 \mathrm{~g} / \mathrm{cm}^{2}$. Cell viability was determined via Cell Counting Kit-8 assays at 0, 12, 24, 48 and 72 h. The expression levels of Smad4, caspase-3 and Bcl-2 were measured via reverse transcription-quantitative PCR and western blotting. The application of compressive force on HGFs for $24 \mathrm{~h}$ resulted in a significant increase in cell proliferation and Bcl-2 expression, but a significant decrease in the expression of Smad4 and caspase-3; however, inverse trends were observed by $72 \mathrm{~h}$. Subsequently, a lentivirus was used to overexpress Smad4 in HGFs, which attenuated the effects of compressive force on HGF proliferation and $\mathrm{Bcl}-2$ expression, but enhanced caspase- 3 expression, suggesting that Smad4 may regulate compressive force-induced apoptosis in HGFs. In conclusion, these findings increased understanding regarding the mechanisms of compressive force-induced HGF proliferation and apoptosis, which may provide further insight for improving the efficacy and stability of orthodontic treatment.
\end{abstract}

\section{Introduction}

In orthodontic treatment, force is applied to the teeth using appliances and transmitted to the periodontal tissues, which eventually leads to tissue reconstruction of the gingiva,

Correspondence to: Professor Shuixue Mo, Department of Stomatology, Guangxi Medical University, 10 Shuangyong Road, Nanning, Guangxi 530021, P.R. China

E-mail: msx0226@163.com

Key words: human gingival fibroblasts, poly(lactide-co-glycolide), Smad4, caspase-3, Bcl-2, compression pressure periodontal ligaments and alveolar bone, thereby moving the misaligned teeth to their normal positions (1). The adaptive reconstruction of periodontal tissue is the biological basis of tooth movement (2). As an important part of the periodontal tissue, gingiva is often involved in the process of orthodontic treatment, such as gingiva proliferation, recession and retraction. Such malformations persist for a number of years after treatment (3). Gingival reconstruction not only affects the rate of tooth movement and the stability after correction $(4,5)$, but also leads to recurrence after orthodontic treatment (6).

Orthodontic pressure is converted into biological signals, which are transmitted from the extracellular to the intracellular environment, inducing a series of associated signal transduction reactions that affect the process of gingival tissue remodeling (7). Human gingival fibroblasts (HGFs) are the main cells in the gingival tissue, where they receive and transmit signals (8). In previous decades, although a number of groups have widely studied the reconstruction of alveolar bone and periodontal membrane under compressive force (9), mechanisms underlying gingival reconstruction remain largely unexplored. Our previous study showed that compressive force could promote the expression of transforming growth factor (TGF)- $\beta 1$ and the proliferation of HGFs (10). TGF- $\beta$ is an important growth factor that regulates cell proliferation and apoptosis $(11,12)$; however, the factors and signaling pathways involving TGF- $\beta$ that regulate HGF proliferation and apoptosis remain unknown.

Smad4, a key downstream factor of TGF- $\beta$ signaling pathway, plays a crucial regulatory role (13). In the classical TGF- $\beta$ pathway, activated Smad $2 / 3$ and Smad 4 form the SMAD complex, which translocates to the nucleus (14). Smad4 is considered to be a tumor suppressor gene that is closely related to cell apoptosis (15-17). Imbalance of Smad4 expression in the TGF- $\beta$ signaling pathway may lead to various diseases, including cancers, fibrous lesions, metabolic diseases and cardiovascular diseases (18-21). It has been found that Smad4 affects apoptosis by regulating apoptosis-related proteins; for example, the low expression of Smad4 in colon cancer can inhibit cell apoptosis by promoting $\mathrm{Bcl}-2$ and $\mathrm{Bcl}-\mathrm{w}$ expression, and decreasing caspase-3 and caspase-9 expression (22). Therefore, it is hypothesized that Smad4 may play a pivotal role in the proliferation and apoptosis of HGFs under compressive force.

Biodegradable poly(lactide-co-glycolide) (PLGA) has become one of the most widely used biological scaffold 
materials (23-26). Compared with other scaffold materials, PLGA possesses good biological properties (27-29). Compared with a two-dimensional culture, a three-dimensional (3D) culture can more effectively mimic the natural environment within the human body, and improve the accuracy and reliability of experimental results. Therefore, a 3D HGF-PLGA culture model was established to explore the roles of Smad4, caspase- 3 and $\mathrm{Bcl}-2$ in regulating proliferation and apoptosis pathways in HGFs. The present study aimed to further understand the molecular mechanisms underlying orthodontic gingival reconstruction.

\section{Materials and methods}

$3 D$ culture of HGFs. HGFs were cultured in 3D PLGA as previously reported (10). Normal gingival tissues were collected from healthy teeth that received orthodontic extraction or gingival resection. Patients enrolled in the study had no systemic diseases, and were aged 10-14 years, with 17 males and 19 females. Normal gingival tissues were cut into small pieces $(1 \times 3 \mathrm{~mm})$ and spread flat in culture flasks. Dulbecco's modified Eagle's medium (HyClone; Cytiva) with $20 \%$ fetal bovine serum (FBS; Gibco; Thermo Fisher Scientific, Inc.) and $100 \mathrm{U} / \mathrm{ml}$ antibiotics (Gibco; Thermo Fisher Scientific, Inc.) were put into the flasks for primary culture. After the primary cells had proliferated, they were digested with $0.25 \%$ trypsin (Sigma-Aldrich; Merck KGaA) containing $100 \mathrm{ng} / \mathrm{ml}$ DNase (Roche Diagnostics) for $1 \mathrm{~min}$. The digestion was stopped by adding Dulbecco's modified Eagle's medium with $10 \%$ FBS and $100 \mathrm{U} / \mathrm{ml}$ antibiotics. Cells were cultured at $37^{\circ} \mathrm{C}$ with $5 \% \mathrm{CO}_{2}$. PLGA scaffolds (molar ratio, 75:25; pore diameter, $100-200 \mu \mathrm{m}$; porosity, $85 \%$; size, $2 \times 2 \mathrm{~cm} \times 300 \mu \mathrm{m}$; Shandong Medical Instrument Research Institute) were cut into $1 \times 1 \times 0.2 \mathrm{~cm}$ sizes. All donors and their guardians provided written informed consent, and samples were collected between March 2018 and March 2019 at the Department of Oral and Maxillofacial Surgery of the Stomatological Hospital affiliated to Guangxi Medical University (Nanning, China).

Application of compressive force. After 4-6 generations, HGFs were digested, and then the cell count was adjusted to $1 \times 10^{5} / \mathrm{ml}$. HGF suspension $(0.5-1 \mathrm{ml})$ was dripped on each piece of PLGA scaffold to enable more cells to attach to the scaffold. The scaffold was stored in an incubator for $2 \mathrm{~h}$ at $37^{\circ} \mathrm{C}$. After confirming that the cells were stably attached to the PLGA, the PLGA were cultured in 6-well plates with $1 \mathrm{ml}$ containing $10 \%$ fetal bovine serum medium for a further $24 \mathrm{~h}$ in an incubator with a constant temperature of $37^{\circ} \mathrm{C}$. HGFs were continuously subjected to a compressive stress of $25 \mathrm{~g} / \mathrm{cm}^{2}$ for $12,24,48$ and $72 \mathrm{~h}$ by placing glass bottles containing lead granules on the top, as showed in Fig. 1.

Cell viability. HGFs were seeded into 96-well plates and the cell count was adjusted to $5 \times 10^{4}$ cells/well. Then, Cell Counting Kit-8 (CCK-8) assays were performed after 0, 12, $24,48$ and $72 \mathrm{~h}$ of compressive force. CCK-8 solution (10 $\mu \mathrm{l})$ was added to each well (1:10), and the cells were cultured for an additional $2 \mathrm{~h}$ before measuring the absorbance using a microplate reader (Model 3550; Thermo Fisher Scientific, Inc.) at $450 \mathrm{~nm}$.
Overexpression of Smad4 in HGFs. After 4-6 generations, HGFs were digested, and the cell count was adjusted. HGFs were seeded in 96-well plates with $5 \times 10^{3}$ cells/well and cultured for $12 \mathrm{~h}$. Then, lentivirus ( $\mathrm{Lv}$-control or Lv-Smad4; plasmid backbone, GV492; Shanghai GeneChem Co., Ltd.) and transfection enhancement solution HiTrans A (Shanghai GeneChem Co., Ltd.) was added (MOI=50). After $24 \mathrm{~h}$, aspirate the supernatant in the culture plate and replace with a new serum medium. Additionally, a blank control group constituting normal HGFs was included in the study. The infection efficiency was observed via green fluorescence using a fluorescence microscope (Olympus Corporation) $72 \mathrm{~h}$ after infection. Reverse transcription-quantitative (RT-q)PCR and western blotting (WB) were performed to analyze Smad4 expression at the mRNA and protein levels.

$R T-q P C R$. Total RNA from HGFs was isolated using TRIzol ${ }^{\circledR}$ reagent (Invitrogen; Thermo Fisher Scientific, Inc.). Then, RNA quality was tested using an RNA 6000 Nano kit (Agilent Technologies, Inc.). cDNA was synthesized using an ExScript RT reagent kit (Takara Bio, Inc.), according to the manufacturer's protocol $\left(37^{\circ} \mathrm{C}\right.$ for $15 \mathrm{~min}$ and $85^{\circ} \mathrm{C}$ for $5 \mathrm{sec}$, followed by storage at $4^{\circ} \mathrm{C}$ until further use. The RT-qPCR was performed on an ABI 7300 Real-Time PCR system (Applied Biosystems; Thermo Fisher Scientific, Inc.) with SYBR Premix Ex Taq (Takara Biotechnology Co., Ltd.) at $95^{\circ} \mathrm{C}$ for $30 \mathrm{sec}$, followed by 40 cycles at $95^{\circ} \mathrm{C}$ for $5 \mathrm{sec}$ and $60^{\circ} \mathrm{C}$ for $31 \mathrm{sec}$, after which a melt curve analysis was performed at $95^{\circ} \mathrm{C}$ for $15 \mathrm{sec}, 60^{\circ} \mathrm{C}$ for $1 \mathrm{~min}$ and $95^{\circ} \mathrm{C}$ for $15 \mathrm{sec}$. The primer sequences were: Smad4 forward, 5'-TGGTAGGATTGTGAGGATTAAATC AG-3' and reverse, 5'-ACCATCCTAACACACCTAATTTAG TC-3'; caspase-3 forward, 5'-CCTAGCGGATGGGTGCTA TT-3' and reverse, 5'-CTGAGGTTTGCTGCATCGAC-3'; Bcl-2 forward, 5'-AATATCCAATCCTGTGCTGCTA-3' and reverse, 5'-GTCCACGTTCTTCATTGTTACTTC-3'; and GAPDH forward, 5'-TGTGTCCGTCGTGGATCTGA-3' and reverse, 5'-TTGCTGTTGAAGTCGCAGGAG-3'. All reactions were performed in triplicate and GAPDH was used as an internal control. Each experiment was repeated at least three times. The relative expression level was calculated using the $2^{-\Delta \Delta \mathrm{Cq}}$ method (30).

WB. Total protein was extracted from cells using RIPA lysis buffer with PMSF (1,000:1; Pierce; Thermo Fisher Scientific, Inc.). The protein concentration was detected using a BCA assay. Proteins (30 $\mu \mathrm{g} / \mathrm{sample})$ and marker (5 $\mu \mathrm{l})$ were loaded onto $10 \%$ SDS-PAGE gels. Electrophoresis was conducted under a constant voltage of $200 \mathrm{~V}$ for $45 \mathrm{~min}$. Proteins were transferred to PVDF membranes at $200 \mathrm{~mA}$ for $1.5 \mathrm{~h}$. TBS- $0.3 \%$ Tween- 20 was used to wash the PVDF membranes 3 times $(5 \mathrm{~min} /$ wash). Membranes were then blocked in 5\% skimmed milk for $1 \mathrm{~h}$ at room temperature before being incubated with monoclonal antibodies against human Smad4 (1:1,000; cat. no. ab40759; Abcam), Bcl-2 (1:1,000; cat. no. 4223S; Cell Signaling Technology, Inc.), caspase-3 (1:5,000; cat. no. ab32351; Abcam) and GAPDH (1:5,000; cat. no. SAB4300645; Sigma-Aldrich; Merck KGaA) for overnight incubation at $4{ }^{\circ} \mathrm{C}$, followed by incubation for $1 \mathrm{~h}$ at room temperature with secondary anti-mouse/rabbit horseradish peroxidase-conjugated antibodies (1:5,000; 
cat. nos. SA00001-1/SA00001-2; ProteinTech Group, Inc.). After several washes, protein bands were visualized using an Alpha Chemical Luminescent Gel Imaging System (Fluor Chem HD2; ProteinSimple) with ECL luminescence reagent (cat. no. abs920; Absin Bioscience, Inc.), The relative density of protein expression was analyzed quantitatively with Image Lab v3.0 software (Bio-Rad Laboratories, Inc.).

Statistical analysis. SPSS 21 (IBM Corp.) was used for statistical analysis of experimental data. Data are presented as the mean \pm SD of at least three independent experiments. Data were analyzed using one-way or two-way ANOVA with post hoc tests (Dunnett's or Tukey) for multiple comparisons. $\mathrm{P}<0.05$ and $\alpha=0.05$ were considered to indicate a statistically significant difference.

\section{Results}

Compressive force induces the proliferation of HGFs. A 3D PLGA-HGFs culture model was previously established by our group as showed in Fig. 1 (10). Compared with the control group $(0 \mathrm{~h})$, the proliferation ability of HGFs significantly increased under compressive force for 12,24 and $48 \mathrm{~h}$, peaking at $24 \mathrm{~h}$. Subsequently, the proliferation of HGFs was inhibited and cell viability decreased by $72 \mathrm{~h}(\mathrm{P}<0.05$; Fig. 2$)$.

Compressive force decreases the expression of Smad4 in $H G F$. The gene and protein expression of Smad4 decreased significantly following exposure to compressive force, reaching its lowest level at $24 \mathrm{~h}$. Subsequently, the expression levels increased at 48 and $72 \mathrm{~h}(\mathrm{P}<0.05$; Fig. 3).

Expression of caspase- 3 and Bcl-2 changed in response to compressive force in HGFs. The gene and protein expression of caspase-3 decreased significantly, reaching its lowest level at $24 \mathrm{~h}$. Subsequently, its expression was increased at 48 and $72 \mathrm{~h}$. However, the gene and protein expression of Bcl-2 increased significantly compared with the control group, peaking at $24 \mathrm{~h}$. Subsequently, the expression levels gradually decreased $(\mathrm{P}<0.05$; Fig. 4).

Assessment of Smad4 mRNA and protein levels. At $72 \mathrm{~h}$ after transfection of HGFs with Lv-Smad4, the expression efficiency of enhanced green fluorescent protein was $\sim 90 \%$ (Fig. 5). Furthermore, gene and protein expression analysis revealed that the levels of Smad4 (Fig. 6) were significantly upregulated in the Lv-Smad4 group compared with the Lv-control and blank control groups $(\mathrm{P}<0.01)$. The expression levels in the Lv-control group significantly decreased compared with the control cells $(\mathrm{P}<0.05)$, which indicated that the lentiviral system effectively delivered the exogenous Smad4 gene.

Smad4 overexpression inhibits the effects of compressive force on $H G F$ proliferation. The CCK- 8 assay results showed that the absorbance values of HGFs increased with the increased culture time $(\mathrm{P}<0.05$; Fig. $7 \mathrm{~A})$. In the first two days, the difference in optical density (OD) values between the Lv-Smad4, Lv-control and control groups were not statistically significant. However, the OD value of the Lv-Smad4 group decreased compared with the Lv-control and control groups

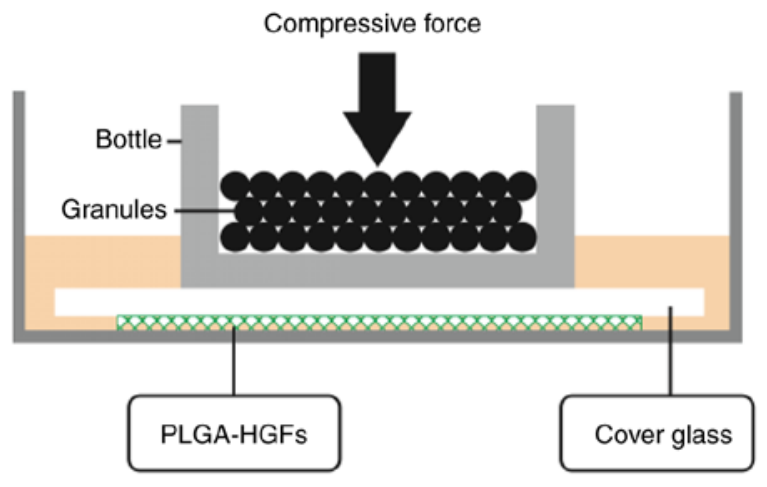

Figure 1. Schematic of compressive force loading. PLGA-HGF, poly(lactide-co-glycolide) human gingival fibroblast.

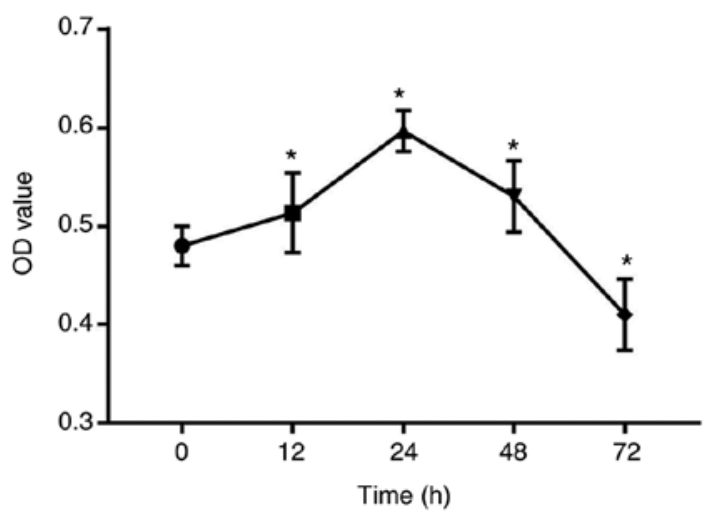

Figure 2. Compressive force induces the proliferation of HGFs. Proliferation of HGFs under $25 \mathrm{~g} / \mathrm{cm}^{2}$ compressive force for $0,12,24,48$ and $72 \mathrm{~h}$ was analyzed via Cell Counting Kit- 8 assays. One-way ANOVA followed by Dunnett's post hoc test was used to analyze data. ${ }^{*} \mathrm{P}<0.05$ vs. $0 \mathrm{~h}$. HGF, human gingival fibroblast; OD, optical density.

from day 3onwards $(\mathrm{P}<0.05)$. Additionally, all three groups were significantly different to each other from day 5 onwards, with the highest OD values in the control group and the lowest in the Lv-Smad4 group $(\mathrm{P}<0.05)$. Furthermore, the CCK-8 results revealed the participation of Smad4 in HGF proliferation induced by compressive force, as shown in Fig. 7B. There was no significant increase in HGF proliferation in the $\mathrm{Lv}-\mathrm{Smad} 4$ group after $24 \mathrm{~h}$ of compressive force compared with before force was applied ( $\mathrm{P}>0.05$; Fig. 7B). Conversely, in the Lv-control and Lv-Smad4 groups, stimulation with continuous compressive force for $24 \mathrm{~h}$ significantly increased HGF proliferation $(\mathrm{P}<0.05$; Fig. 7B).

Smad4 overexpression reverses the expression of caspase- 3 and Bcl-2 in HGFs. To determine whether Smad4 mediates caspase-3 and Bcl-2 expression under compressive force, Smad4 was overexpressed in HGFs. Although continuous compressive force stimulation for $24 \mathrm{~h}$ significantly decreased the expression of Smad4 in the Lv-Smad4 group, Smad4 expression was upregulated compared with in the Lv-control and control groups. Furthermore, it was demonstrated that with or without compressive force stimulation, the expression levels of Bcl-2 and caspase-3 were downregulated and upregulated, respectively, in the Lv-Smad4 group compared with the control group (Fig. 8). These findings indicated that Smad4 is 

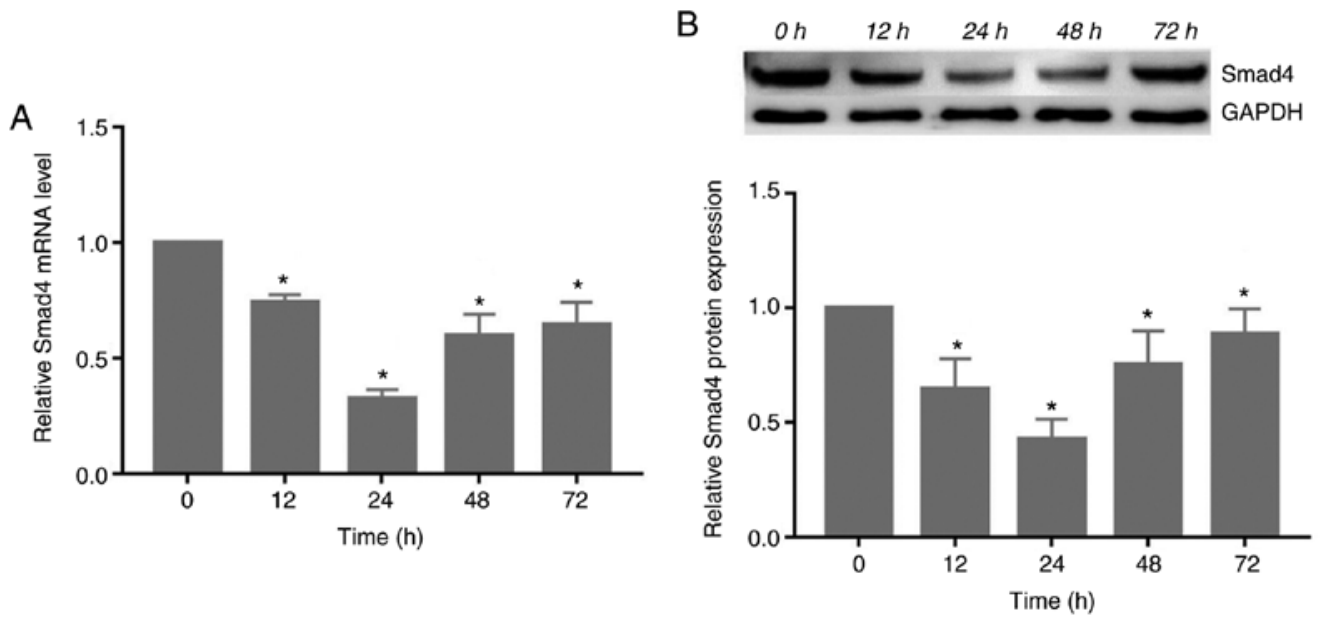

Figure 3. Compressive force regulates Smad4 expression in HGFs in a time-dependent manner. (A) mRNA and (B) protein expression of Smad4 in HGFs under compressive force. One-way ANOVA followed by Dunnett's post hoc test was used to analyze data. ${ }^{\text {P }}<0.05$ vs. 0 h. HGF, human gingival fibroblast.
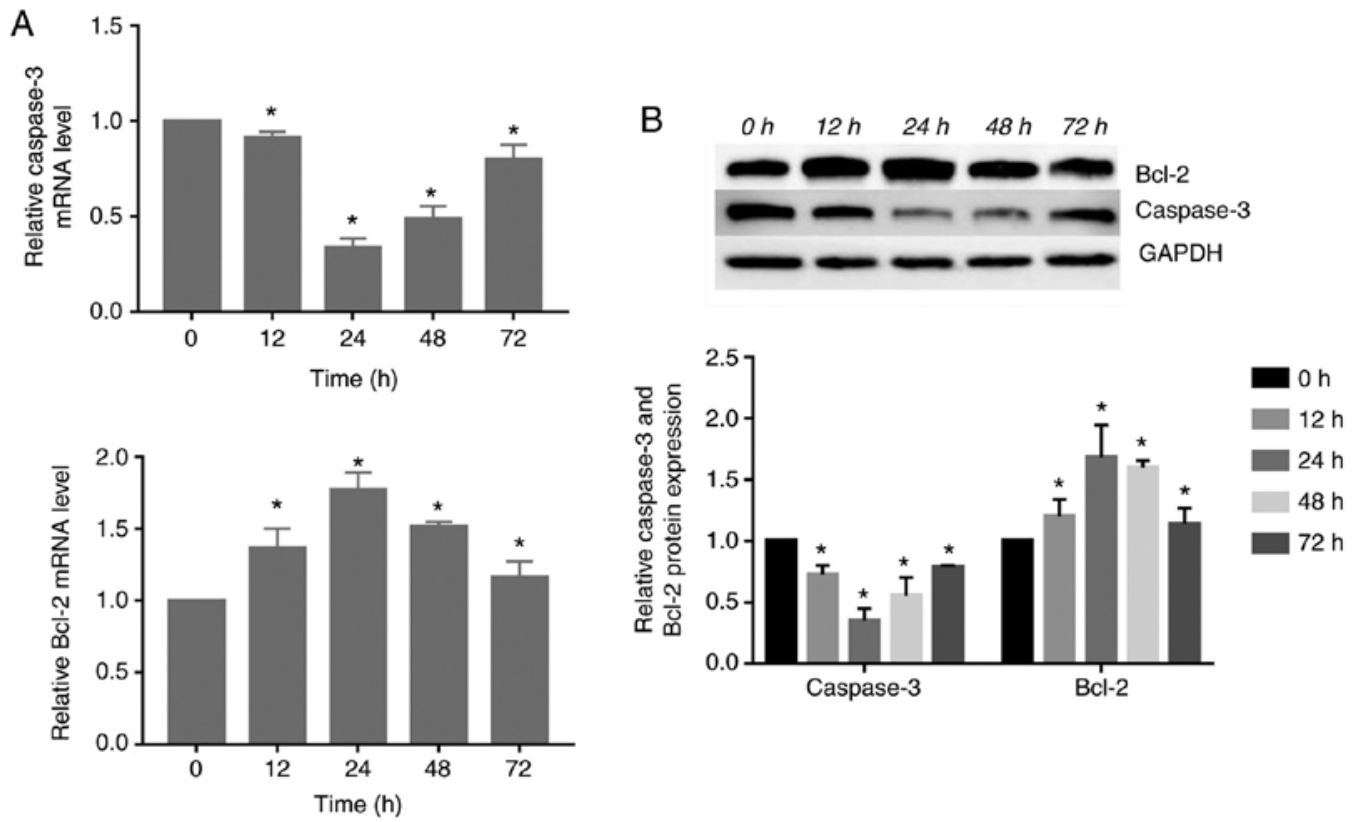

Figure 4. Compressive force regulates apoptosis-associated protein expression in HGFs in a time-dependent manner. (A) mRNA and (B) protein expression of caspase-3 and Bcl-2 in HGFs under compressive force. One-way ANOVA followed by Dunnett's post hoc test was used to analyze data. "P<0.05 vs. 0 h. HGF, human gingival fibroblast.

an important apoptosis-associated factor in HGFs; compressive force inhibited HGF apoptosis and promoted proliferation by downregulating the expression of Smad4.

\section{Discussion}

Clinically, gingival hyperplasia and accumulation of the stressed side are commonly found during orthodontic treatment (1-4). Exploring this phenomenon, Schwarz (31) reported that when the orthodontic force did not exceed the end capillary pressure of the periodontal ligament on the root surface of the tooth, it was most conducive to the movement of teeth, and exceeding this threshold results in the necrosis of periodontal tissue. In the human body and most mammals, this pressure is $\sim 20-26 \mathrm{~g} / \mathrm{cm}^{2}$. Therefore, it has been proposed that under reasonable pressure, weight loading models can more effectively simulate changes in the periodontal tissue on the compressed side of the body $(32,33)$. For example, Kook et al (34) and Li et al (35) used force-loading models to demonstrate that the proliferative ability of periodontal ligament fibroblasts is enhanced under suitable compressive pressure stimulation. In addition, Baker et al (36) reported that the elastic modulus of porous PLGA scaffolds is $\sim 4 \mathrm{MPa}$, which is close to the elastic modulus of human gingival tissue (37). Therefore, the present study was conducted based on these findings and early experimental results of our research group, such as a PLGA-HGFs 3D culture model, an optimal value of $25 \mathrm{~g} / \mathrm{cm}^{2}$ and high expression of TGF- $\beta 1$ (10).

Studies have found that Smad4 is closely related to cell proliferation and apoptosis (15-17). It has been found in tumor research that Smad4 is a tumor suppressor gene, and its decreased or absent expression in a variety of tumors has 

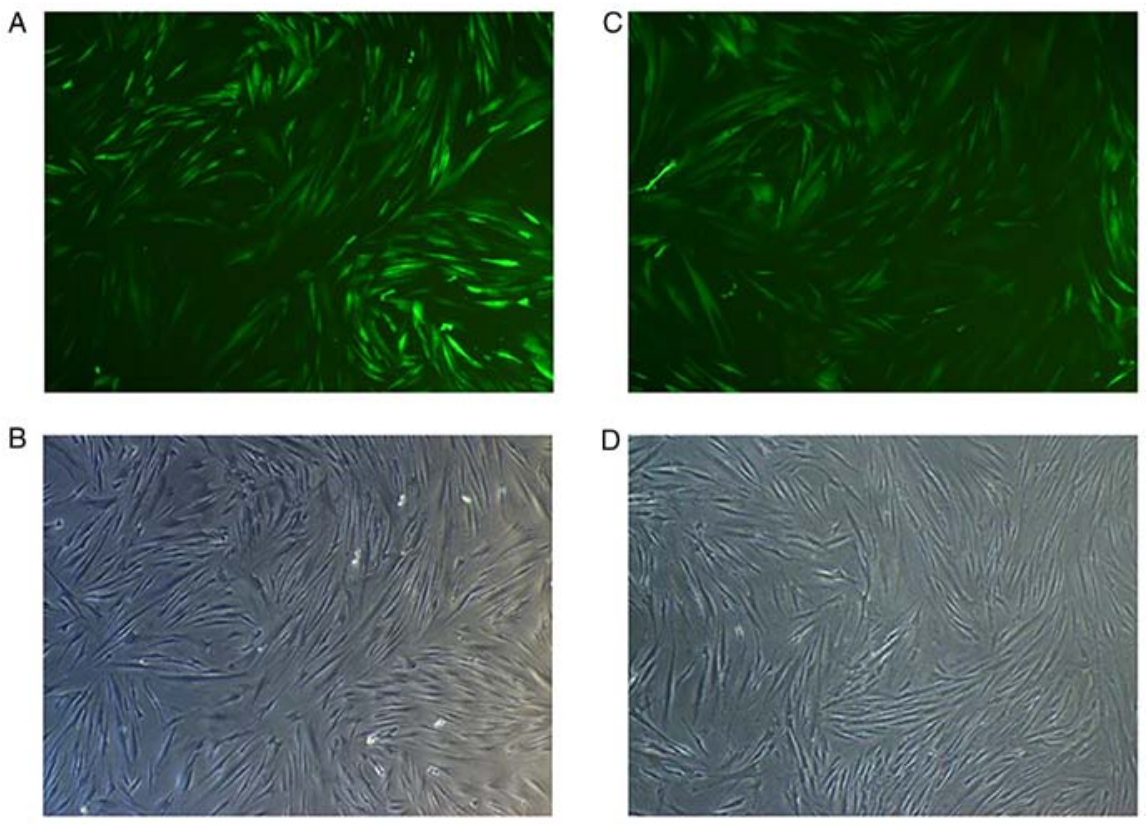

Figure 5. Transfection efficiency of Lv-Smad4 and Lv-control. (A) EGFP fluorescence and (B) appearance under ordinary optical microscope of HGFs infected with Lv-Smad4. (C) EGFP fluorescence and (D) appearance under ordinary optical microscope of HGFs infected with Lv-control. Magnification, x40. EGFP, enhanced green fluorescent protein; HGF, human gingival fibroblast; Lv-, lentivirus.

B

Lv-Smad4 Lv-control Control
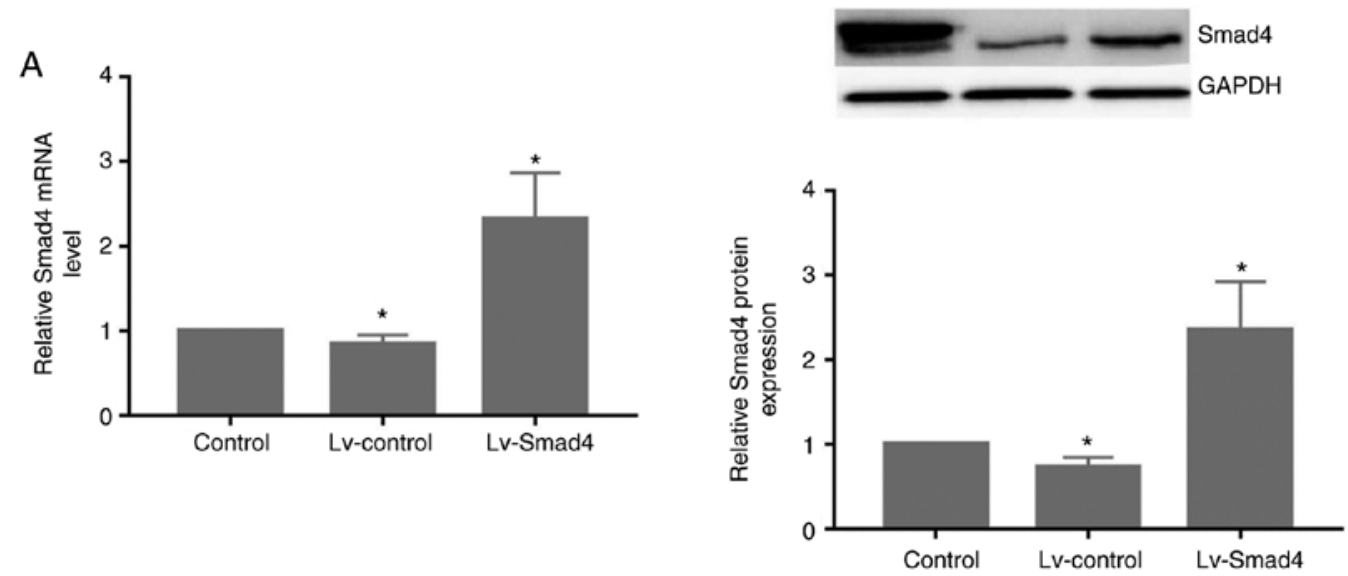

Figure 6. Smad4 gene and protein expression in human gingival fibroblasts following transfection with Lv-Smad4. Relative expression of Smad4 (A) mRNA and (B) protein following transfection with Lv-Smad4, Lv-control or blank control treatment. One-way ANOVA followed by Dunnett's post hoc test was used to analyze data. ${ }^{\mathrm{P}}<0.05$ vs. Control. Lv-, lentivirus.
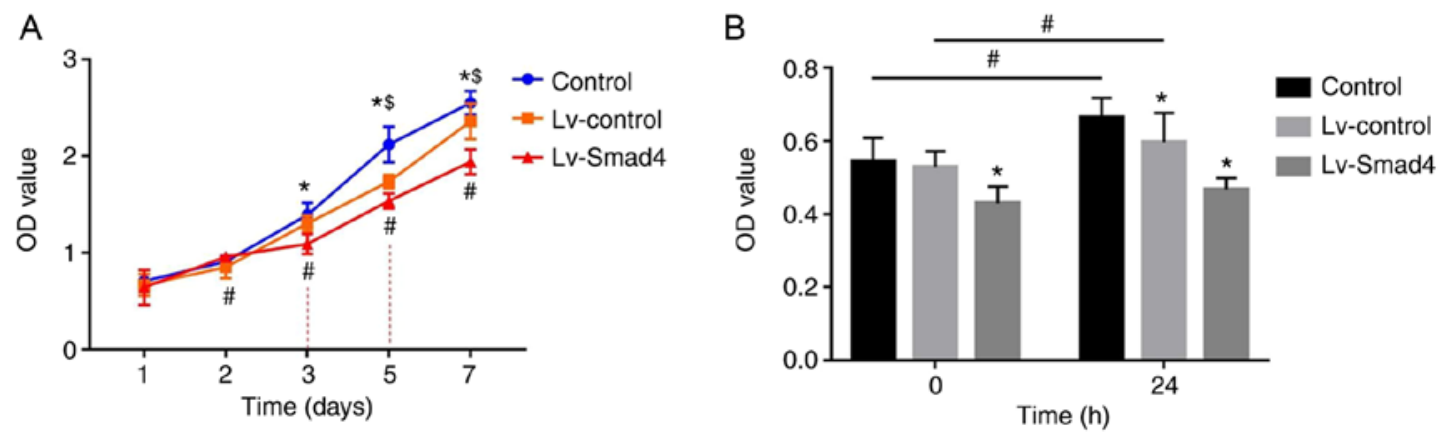

Figure 7. Smad4 overexpression inhibits the effects of compressive force on the proliferation of HGFs. (A) Proliferation of HGFs following lentivirus transfection. Two-way ANOVA with Tukey's post hoc test was used to analyze data. ${ }^{*} \mathrm{P}<0.05$ vs. day $1 ;{ }^{*} \mathrm{P}<0.05$ vs. Lv-Smad4; ${ }^{\text {P }}<0.05$ vs. Lv-control. (B) Proliferation of HGFs under compressive force. Two-way ANOVA with Tukey's post hoc test was used to analyze data. ${ }^{*} \mathrm{P}<0.05$ vs. Control; ${ }^{*} \mathrm{P}<0.05$ vs. 0 h. HGF, human gingival fibroblast; Lv, lentivirus; OD, optical density. 


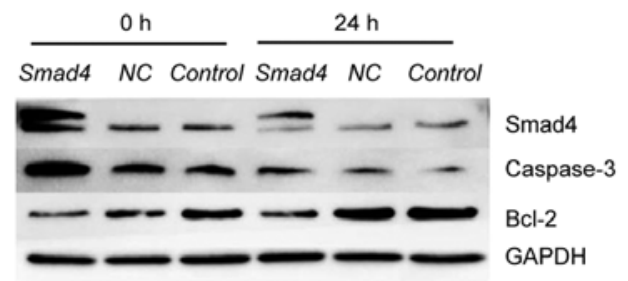

A
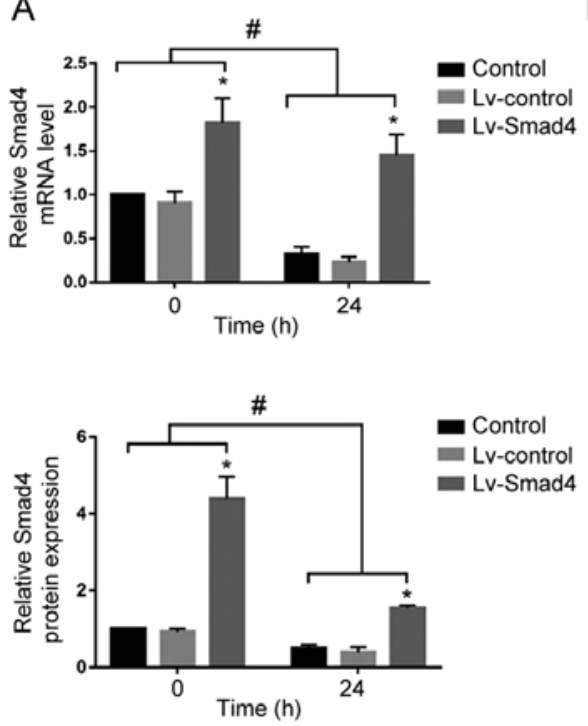

B
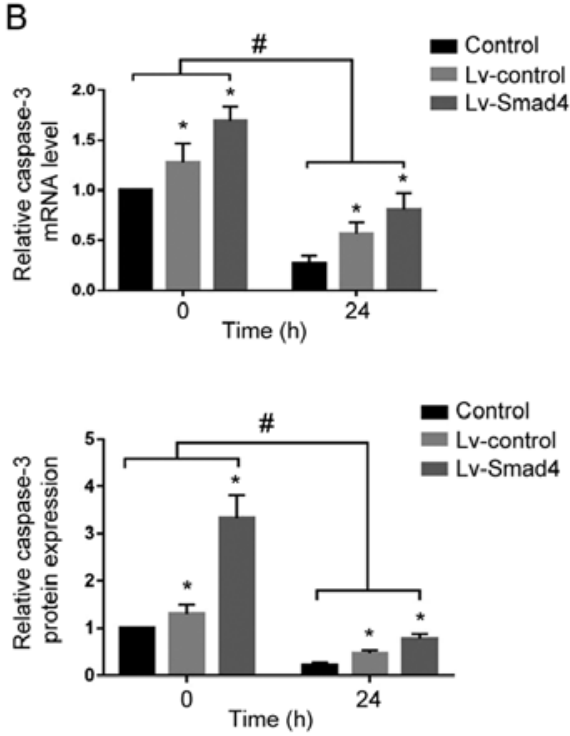

C
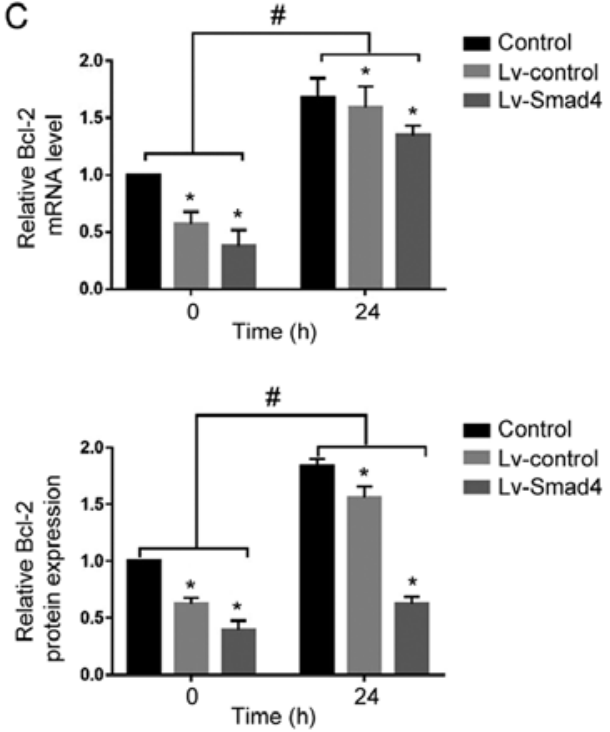

Figure 8. Effect of Smad4 overexpression on the expression of apoptosis-associated proteins. Expression of (A) Smad4, (B) caspase-3 and (C) Bcl-2 gene and protein under compression force. Two-way ANOVA with Tukey's post hoc test was used to analyze data. ${ }^{*} \mathrm{P}<0.05$ vs. Control; ${ }^{\prime} \mathrm{P}<0.05$ vs. $0 \mathrm{~h}$. Lv, lentivirus.

been found to lead to the abnormal proliferation of tissues and cells $(19,20)$; however, it has been found in some studies of cardiovascular diseases that TGF- $\beta 1 / \mathrm{Smad} 4$ can inhibit cell apoptosis. For example, Yin et al (38) silenced Smad4 in human aortic vascular smooth muscle cells (HASMCs) and found that low expression of Smad4 decreased the anti-angiotensin stimulation ability of HASMCs, leading to HASMC migration and apoptosis. Therefore, studies have suggested that the effect of TGF- $\beta 1 / \mathrm{Smad} 4$ signaling on cell apoptosis is dependent on the cell type and environment.

In the present study, HGF proliferation and expression of Smad4 were time-dependent. The proliferation ability of HGF enhanced and peaked after $24 \mathrm{~h}$ of compressive force, then began to decrease with longer exposure. Conversely, the expression of Smad4 decreased and reached a nadir at $24 \mathrm{~h}$, then began to increase. These results suggested that HGFs underwent a series of proliferative and apoptotic processes under compressive force that involved Smad4.

To further explore the relationship between Smad4 and cell proliferation, Smad4 was overexpressed in HGFs. The results of CCK-8 assays revealed that proliferation in the Lv-Smad4 group was significantly decreased compared with in the Lv-control and the control groups from day 3, indicating that Smad4 inhibited the proliferation of HGFs compared with normal cells, which may be due to increased apoptosis. Additionally, the proliferation of HGFs under compressive force was significantly inhibited in the Lv-Smad4 group. These results suggested that Smad4 is associated with the proliferation and apoptosis of HGFs under compressive force, thus highlighting Smad4 as a pro-apoptotic factor in HGFs.
Apoptosis is a gene-regulated programmed cell death process; it is a physiological response of cells to adapt to the environment and maintain the stability of the internal environment of the body (39). There are two main pathways of apoptosis: The mitochondrial pathway and the death receptor pathway. Caspase and Bcl-2 family proteins are involved in both apoptosis pathways $(40,41)$. Caspase-3 plays a key role in promoting apoptosis and is considered the executor of apoptosis (42). The Bcl-2 protein family is a large complex family, mostly located in the mitochondria, endoplasmic reticulum and continuous perinuclear membrane, that mediates the mitochondrial apoptosis pathway (43). Bcl-2 can inhibit apoptosis and is one of the most important oncogenes in apoptotic research (44). It has been reported that downregulated expression of Smad4 in breast cancer can inhibit cell apoptosis by decreasing caspase-3 and caspase-9, and promoting Bcl-2 expression (45). Overexpression of Smad4 in human vascular endothelial cells has shown that Smad4 can inhibit endothelial cell proliferation by promoting caspase-3 activation and blocking the cell cycle (46). However, the role of compressive force and Smad4 in the apoptosis of HGFs, and the relationship between Smad4, caspase-3 and Bcl-2, remain undetermined.

In the present study, the expression of Bcl-2 and caspase-3 were also highly time-dependent. The expression of Bcl-2 was upregulated under compressive force and peaked at $24 \mathrm{~h}$, at which point it began to decrease. Conversely, the expression of caspase- 3 decreased, reaching its lowest point after $24 \mathrm{~h}$ of compressive force stimulation, at which point it began to increase. These results suggested that $\mathrm{Bcl}-2$ and caspase- 3 were 
involved in apoptotic processes in HGFs under compressive force.

It was further shown that, compared with normal cells, caspase-3 expression was increased in the Lv-Smad4 group, while Bcl-2 expression was downregulated. This suggested that Smad4 regulated the expression of caspase- 3 and Bcl-2 in HGFs without compressive force. Furthermore, it was found that Lv-Smad4 cells exhibited downregulated expression of Bcl-2 and upregulated expression of caspase-3 compared with Lv-control and control group cells under compressive force, further suggesting that compressive force regulated the expression of caspase-3 and $\mathrm{Bcl}-2$ via Smad4, thereby regulating HGF proliferation and apoptosis.

In conclusion, the present findings indicated that Smad4 promoted HGF proliferation by regulating caspase- 3 and Bcl-2 under compressive force. Therefore, Smad4 may be an important target for preventing gingival hyperplasia after orthodontic treatment. However, there were certain limitations to the present study. For example, proliferation and apoptosis were only analyzed using CCK-8 assays; additional methods should be used, such as flow cytometry. In addition, the discussion on Smad4 was limited to enhancing the expression of Smad4; subsequent studies should further validate these findings by silencing Smad4.

\section{Acknowledgements}

Not applicable.

\section{Funding}

The present study was supported by grants from the National Natural Science Foundation of China (grant no. 81070860) and the Natural Science Foundation of Guangxi Province (grant no. 2013GXNSFAA019183).

\section{Availability of data and materials}

All data generated or analyzed during this study are included in this published article.

\section{Authors' contributions}

SZ conceived and coordinated the study, designed, performed and analyzed the experiments, and wrote the paper. LN, YW, LW and SM collected and analyzed data, and revised the manuscript. All authors approved the final version of the manuscript, LN and SM confirm the authenticity of all the raw data.

\section{Ethics approval and consent to participate}

The present study was approved by the Hospital Institutional Review Board (approval no. 20150304-22) of Guangxi Medical University. All donors and their guardians signed an informed consent form.

\section{Patient consent for publication}

Not applicable.

\section{Competing interests}

The authors declare that they have no competing interests.

\section{References}

1. Dutra EH, Ahmida A, Lima A, Schneider S, Nanda R and Yadav S: The effects of alveolar decortications on orthodontic tooth movement and bone remodelling in rats. Eur J Orthod 40: 423-429, 2018.

2. Massaeli H, Viswanathan D, Pillai DG and Mesaeli N: Endoplasmic reticulum stress enhances endocytosis in calreticulin deficient cells. Biochim Biophys Acta Mol Cell Res 1866: 727-736, 2019.

3. Redlich M, Shoshan S and Palmon A: Gingival response to orthodontic force. Am J Orthod Dentofacial Orthop 116: 152-158, 1999.

4. Erkan M, Pikdoken L and Usumez S: Gingival response to mandibular incisor intrusion. Am J Orthod Dentofacial Orthop 132: 143.e9-13, 2007.

5. Kalra A, Jaggi N, Bansal M, Goel S, Medsinge SV, Abraham R and Jasoria G: Comparison of rate of canine retraction into recent extraction site with and without gingival fiberotomy: A clinical study. J Contemp Dent Pract 14: 419-426, 2013.

6. Krishnan V, Ambili R, Davidovitch Z and Murphy NC: Gingiva and orthodontic treatment. Semin Orthodont 13: 257-271, 2007.

7. Bartold PM and McCulloch CA: Information generation and processing systems that regulate periodontal structure and function. Periodontol 2000 63: 7-13, 2013.

8. Katsumi A, Naoe T, Matsushita T, Kaibuchi K and Schwartz MA: Integrin activation and matrix binding mediate cellular responses to compressive stretch. J Biol Chem 280: 16546-16549, 2005.

9. Jiang N, Guo W, Chen M, Zheng Y, Zhou J, Kim SG, Embree MC Songhee Song K, Marao HF and Mao JJ: Periodontal ligament and alveolar bone in health and adaptation: Tooth movement. Front Oral Biol 18: 1-8, 2016

10. Nan L, Zheng Y, Liao N, Li S, Wang Y, Chen Z, Wei L, Zhao S and Mo S: Mechanical force promotes the proliferation and extracellular matrix synthesis of human gingival fibroblasts cultured on 3D PLGA scaffolds via TGF- $\beta$ expression. Mol Med Rep 19: 2107-2114, 2019.

11. Aukkarasongsup P, Haruyama N, Matsumoto T, Shiga M and Moriyama K: Periostin inhibits hypoxia-induced apoptosis in human periodontal ligament cells via TGF- $\beta$ signaling. Biochem Biophys Res Commun 441: 126-132, 2013.

12. Xu H, He Y, Feng JQ, Shu R, Liu Z, Li J, Wang Y, Xu Y, Zeng H, $\mathrm{Xu} \mathrm{X}$, et al: Wnt $3 \alpha$ and transforming growth factor- $\beta$ induce myofibroblast differentiation from periodontal ligament cells via different pathways. Exp Cell Res 353: 55-62, 2017.

13. Moustakas A, Souchelnytskyi S and Heldin CH: Smad regulation in TGF-beta signal transduction. J Cell Sci 114: 4359-4369, 2001.

14. Singh P, Srinivasan R and Wig JD: The Smad family and its role in pancreatic cancer. Indian J Cancer 48: 351-360, 2011.

15. Mccarthy AJ and Chetty R: Smad4/DPC4. J Clin Pathol 71: 661-664, 2018.

16. Duda D, Sunamura M, Lefter LP, Furukawa T, Yokoyama T, Yatsuoka T, Abe T, Inoue H, Motoi F, Egawa S, et al: Restoration of SMAD4 by gene therapy reverses the invasive phenotype in pancreatic adenocarcinoma cells. Oncogene 22: 6857-6864, 2003.

17. Hruban RH, Offerhaus GJ, Kern SE, Goggins M, Wilentz RE and Yeo CJ: Tumor-Suppressor genes in pancreatic cancer. J Hepatobiliary Pancreat Surg 5: 383-391, 1998.

18. Michot C, Le Goff C, Mahaut C, Afenjar A, Brooks AS, Campeau PM, Destree A, Di Rocco M, Donnai D, Hennekam R, et al: Myhre and LAPS syndromes: Clinical and molecular review of 32 patients. Eur J Hum Genet 22: 1272-1277, 2014.

19. Ahmed S, Bradshaw AD, Gera S, Dewan MZ and Xu R: The TGF- $\beta /$ Smad 4 signaling pathway in pancreatic carcinogenesis and its clinical significance. J Clin Med 6: 5, 2017.

20. Woodford-Richens KL, Rowan AJ, Gorman P, Halford S, Bicknell DC, Wasan HS, Roylance RR, Bodmer WF and Tomlinson IP: SMAD4 mutations in colorectal cancer probably occur before chromosomal instability, but after divergence of the microsatellite instability pathway. Proc Natl Acad Sci USA 98: 9719-9723, 2001.

21. Shihab FS, Yamamoto T, Nast CC, Cohen AH, Noble NA, Gold LI and Border WA: Transforming growth factor-beta and matrix protein expression in acute and chronic rejection of human renal allografts. J Am Soc Nephrol 6: 286-294, 1995. 
22. Zhang B, Zhang B, Chen X, Bae S, Singh K, Washington MK and Datta PK: Loss of Smad4 in colorectal cancer induces resistance to 5-fluorouracil through activating Akt pathway. Br J Cancer 110: 946-957, 2014.

23. Huang Y,Chen C, Ren J and Ren T: The preparation of poly(lactideco-glycolide)(PLGA)/modified nano-hydroxyapatite(MHA) composite scaffold for tissue engineering. J Funct Materials 38: 629-632, 2007 (In Chinese).

24. Sachar A, Strom TA, San Miguel S, Serrano MJ, Svoboda KK and Liu X: Cell-matrix and cell-cell interactions of human gingival fibroblasts on three-dimensional nanofibrous gelatin scaffolds. J Tissue Eng Regen Med 8: 862-873, 2014.

25. Wei G, Jin Q, Giannobile WV and Ma PX. Nano-fibrous scaffold for controlled delivery of recombinant human PDGF-BB J Control Release 112: 103-110. 2006.

26. Guo N, Zhang Q, Sun Y and Yang H. Separation and identification of acylated leuprorelin inside PLGA microspheres. Int J Pharm 560: 273-281, 2019.

27. Xie H, Gu Z, Li C, Franco C, Wang J, Lia L, Meredith N, Ye Q and Wang $\mathrm{C}$ : A novel bioceramic scaffold integrating silk fibroin in calcium polyphosphate for bone tissue-engineering. Ceram Int 42: 2386-2392, 2016.

28. Alyaa A, Mehjabeen A, Kannan M, Yeb Q and Blawertc C: Biodegradable polymer for sealing porous PEO layer on pure magnesium: An in vitro degradation study. Appl Surf Sci 301: 463-467, 2014

29. Liu Z, Yin $X$, Ye Q, He W, Ge M, Zhou X, Hu J and Zou S: Periodontal regeneration with stem cells-seeded collagen-hydroxyapatite scaffold. J Biomater Appl 31: 121-131, 2016.

30. Livak KJ and Schmittgen TD: Analysis of relative gene expression data using real-time quantitative PCR and the 2(-Delta Delta C(T)) method. Methods 25: 402-408, 2001.

31. Schwarz AM: Tissue changes incidental to orthodontic tooth movement. Int J Orthod Oral Surg Radiog 18: 331-352, 1932.

32. Otero L, García DA and Wilches-Buitrago L: Expression and presence of OPG and RANKL mRNA and protein in human periodontal ligament with orthodontic force. Gene Regul Syst Bio 10: 15-20, 2016

33. Grant M, Wilson J, Rock P and Chapple I: Induction of cytokines, MMP9, TIMPs, RANKL and OPG during orthodontic tooth movement. Eur J Orthod 35: 644-651, 2013.

34. Kook SH, Jang YS and Lee JC: Human periodontal ligament fibroblasts stimulate osteoclastogenesis in response to compression force through TNF- $\alpha$-mediated activation of $\mathrm{CD}^{+} \mathrm{T}$ cells J Cell Biochem 112: 2891-2901, 2011.
35. Li M, Yi J, Yang Y, Zheng W, Li Y and Zhao Z: Investigation of optimal orthodontic force at the cellular level through three-dimensionally cultured periodontal ligament cells. Eur J Orthod 38: 366-372, 2016.

36. Baker SC, Rohman G, Southgate J and Cameron NR: The relationship between the mechanical properties and cell behaviour on PLGA and PCL scaffolds for bladder tissue engineering. Biomaterials 30: 1321-1328, 2009.

37. Subbarayan R, Murugan Girija D, Mukherjee J, Mamidanna SRR and Ranga Rao S: Comparision of gingival and umbilical cord stem cells based on its modulus and neuronal differentiation. J Cell Biochem 118: 2000-2008, 2017.

38. Yin P, Wang Y and Shen Z: SMAD4 gene silencing promotes human vascular smooth muscle cells migration and apoptosis. J Jiangsu Univ (Medicine Edition) 28: 26-29, 2018 (In Chinese).

39. Grilo AL and Mantalaris A: Apoptosis: A mammalian cell bioprocessing perspective. Biotechnol Adv 37: 459-475, 2019.

40. Cohen JJ, Duke RC, Fadok VA and Sellins KS: Apoptosis and programmed cell death in immunity. Annu Rev Immunol 10: 267-293, 1992

41. Zhang Y, Alexander PB and Wang XF: TGF-beta family signaling in the control of cell proliferation and survival. Cold Spring Harb Perspect Biol 9: a022145, 2017.

42. Mcilwain DR, Berger T and Mak TW: Caspase functions in cell death and disease. Cold Spring Harb Perspect Biol 7: a026716, 2015.

43. Ashkenazi A, Fairbrother WJ, Leverson JD and Souers AJ. From basic apoptosis discoveries to advanced selective BCL-2 family inhibitors. Nat Rev Drug Discov 16: 273-284, 2017.

44. Taylor RC, Cullen SP and Martin SJ: Apoptosis: Controlled demolition at the cellular level. Nat Rev Mol Cell Biol 9: 231-241, 2008.

45. Liu N, Li Y, Li R, Sun L and Liu X: Influence of silencing Smad4 gene in proliferation and apoptosis of breast carcinoma MCF-7 cells. J Jilin Univ (Medical Edition) 43: 887-892, 2017 (In Chinese).

46. Demagny H and De Robertis EM: Point mutations in the tumor suppressor Smad4/DPC4 enhance its phosphorylation by GSK3 and reversibly inactivate TGF- $\beta$ signaling. Mol Cell Oncol 3: e1025181, 2015

This work is licensed under a Creative Commons Attribution-NonCommercial-NoDerivatives 4.0 International (CC BY-NC-ND 4.0) License. 